\title{
Identificação de Benchmarks e anti-Benchmarks para companhias aéreas usando modelos DEA e fronteira invertida
}

\author{
Juliana Quintanilha da Silveira ${ }^{a *}$, Lidia Angulo Meza ${ }^{\mathrm{b}}$, \\ João Carlos Correia Baptista Soares de Melloc \\ a*juliqs@hotmail.com, UFF, Brasil \\ blidia_a_meza@pq.cnpq.br, UFF, Brasil \\ cjcsmello@pq.cnpq.br, UFF, Brasil
}

\begin{abstract}
Resumo
0 crescente aumento da competitividade do setor de transporte aéreo nos últimos anos tem provocado uma mudança na dinâmica de mercado, levando as companhias aéreas a buscar novas estratégias para garantir a sua posição. Este artigo tem o objetivo de analisar o desempenho das companhias aéreas brasileiras no que tange à sua gestão operacional, após a crise do setor, ocorrida em 2006. A eficiência das empresas aéreas em 2007 foi avaliada através da comparação dos resultados obtidos no modelo de Análise Envoltória de Dados (Data Envelopment Analysis - DEA) clássico com os calculados pelo método da fronteira invertida. Este artigo inclui ainda a identificação das companhias com as melhores e piores práticas gerenciais.
\end{abstract}

Palavras-chave

Transporte aéreo. Análise Envoltória de Dados. Benchmarking.

\section{Introdução}

0 setor de transporte aéreo no Brasil tem passado por transformações estruturais significativas desde o início da década de 90 . O setor assistiu a um processo de desregulamentação, que rompeu com a política vigente, instalada desde o final dos anos 60, na qual a estrutura e a conduta de mercado eram controladas e associadas a mecanismos de política industrial (OLIVEIRA, 2007).

0 início desse processo ocorreu a partir da abolição dos monopólios regionais em 1992. Dessa forma, foi estimulada a entrada de novas operadoras, além da competição em preços, com a definição de bandas tarifárias. No final dos anos 90, a desregulamentação teve um novo impulso (COELHO, 2002) e foram removidas as bandas tarifárias e a exclusividade ainda existente na operação de algumas linhas aéreas para companhias regionais. Essas medidas acirraram ainda mais a competição entre empresas. Em 2001, houve uma total liberalização dos preços, a flexibilização dos processos de entrada de novas firmas e de pedidos de novas linhas aéreas, frequências de voo e aviões, resultando inclusive na entrada da Gol, a primeira Low Cost Carrier (LCC) em janeiro de 2001 (EVANGELHO; HUSE; LINHARES, 2005).

No ano de 2006, o setor assistiu a um período de grande crise provocada principalmente pelas dificuldades financeiras de uma das maiores companhias aéreas brasileiras, a Varig, e pela queda do avião da Gol, em setembro deste mesmo ano. Em poucos meses, a Varig deixou de operar várias rotas domésticas e internacionais. lsso gerou dificuldades no atendimento da demanda por parte das demais companhias aéreas que não foram capazes de absorver os passageiros deixados pela Varig.

Ainda em 2006, o controle de tráfego aéreo brasileiro passou por sérias dificuldades causadas pela falta de planejamento e pela insuficiência de recursos. As principais consequências para o transporte aéreo foram atrasos e cancelamentos de voos, além de problemas nos aeroportos. 
Essas mudanças intensificam ainda mais a competição estabelecida entre as companhias de transporte aéreo e induzem à busca pelo melhor desempenho, levando as empresas ao desenvolvimento de novas estratégias para garantir sua posição no mercado.

0 presente artigo tem como objetivo avaliar o desempenho das companhias aéreas brasileiras para o transporte aéreo de passageiros e cargas, no ano de 2007, após a crise do setor. Para isso, será aplicada a Análise Envoltória de Dados (DEA) às companhias operantes no ano em questão e o modelo da fronteira invertida, de Yamada, Matui e Sugiyama (1994) e Entani, Maeda e Tanaka (2002), buscando o aumento da capacidade discriminatória do método clássico na avaliação das eficiências operacionais das companhias. Além disso, a fronteira DEA clássica permite identificar as companhias com as melhores práticas (benchmarks) e a fronteira invertida as empresas com as piores práticas de gestão neste ano (anti-benchmarks). Evidentemente essas melhores e piores práticas são em relação aos inputs e outputs considerados no modelo.

0 artigo foi organizado da seguinte forma: na seção 2 há uma revisão do modelo DEA clássico. A seção 3 discute o método da fronteira invertida e seu uso na melhora da discriminação em DEA. $\mathrm{Na}$ seção 4 são apresentadas a caracterização e a modelagem do problema. A seção 5 mostra os resultados da aplicação do modelo DEA e da fronteira invertida, além da determinação de alvos e antialvos. Finalmente, na seção 6, são descritas as conclusões do trabalho.

\section{Análise Envoltória de Dados}

A Análise Envoltória de Dados é uma metodologia com base em programação matemática, que tem como objetivo medir a eficiência de um conjunto de unidades produtivas (unidades tomadoras de decisão), denominadas de DMUs (Decision Making Units), que consomem múltiplos inputs (insumos, recursos) para produzir múltiplos outputs (produtos).

Existem dois modelos clássicos em DEA: CCR (também conhecido por CRS ou Constant Return to Scale), proposto por Charnes, Cooper e Rhodes (1978), e BCC (também conhecido por VRS ou Variable Return to Scale) proposto por Banker, Charnes e Cooper (1984). No modelo CCR qualquer variação nos inputs produz variação proporcional nos outputs, considerando-se retornos constantes de escala. Já o modelo $\mathrm{BCC}$ não assume proporcionalidade entre inputs e outputs, permitindo retornos variáveis de escala.
Para o cálculo da eficiência é possível utilizar a orientação a inputs que objetiva produzir a mesma quantidade de produtos minimizando a utilização dos recursos. Por outro lado, a orientação a outputs visa maximizar a produção mantendo constante a quantidade de recursos consumidos.

Neste estudo, será utilizado o modelo BCC que admite retornos variáveis de escala. Essa escolha é devida ao fato de as companhias estudadas usarem aeronaves de tamanhos diversos e rotas de duração muito diferentes. Há um número mínimo de pessoal para operar qualquer aeronave (ou rota) e assim a proporcionalidade entre inputs e outputs, exigida pelo modelo CCR, não existe, o que obriga ao uso do modelo BCC. 0 modelo dos multiplicadores do BCC é apresentado na Equação 1:

$$
\begin{aligned}
& \text { Max Eff }=\sum_{r=1}^{s} u_{r} y_{j o}+u_{*} \\
& \text { Sujeito } a \\
& \sum_{i=1}^{m} v_{i} x_{i o}=1 \\
& \sum_{i=1}^{m} v_{i} x_{i k}-\sum_{r=1}^{s} \mathrm{u}_{r} y_{j k}-u_{*} \geq 0, k=1, \ldots, n \\
& u_{r,} v_{i} \geq 0, \forall r, i \\
& u_{*} \in \Re
\end{aligned}
$$

em que $v_{\mathrm{i}}$ e $u_{\mathrm{r}}$ são os multiplicadores de inputs $i$, $i=1, \ldots, m$, e outputs $r, r=1, \ldots, s$, respectivamente; $x_{i j}$ e $y_{\text {r }}$ são os inputs $i$ e outputs $r$ da DMU $j, j=1, \ldots, n$; $\mathrm{u}_{*}$ é a variável de escala.

Os modelos DEA também identificam as unidades referência (benchmarks) para as organizações que não têm um desempenho eficiente. Isto é, fornecem um conjunto de unidades com modelos de desempenho com os quais a organização pode se comparar, com o objetivo de melhorar a sua performance.

A formulação dos modelos DEA é benevolente, no sentido que cada DMU pode escolher destacar as suas melhores características. Assim é possível que um grande número de DMUs se localize na fronteira eficiente, reduzindo sua capacidade discriminatória. Por determinação empírica, o empate delas acontece principalmente quando o número de DMUs não é muito grande em comparação com o número total de inputs e outputs. Ao longo dos anos, têm-se desenvolvido diferentes modelos com o objetivo de melhorar a discriminação em DEA (ADLER; FRIEDMAN; SINUANY-STERN, 2002; ANGULO-MEZA; LINS, 2002). Um dos métodos que permite essa melhor discriminação, não abordado pelos artigos mencionados anteriormente, é a fronteira invertida que será detalhada na seção a seguir. 


\section{Fronteira invertida}

A fronteira invertida pode ser vista como uma avaliação pessimista das DMUs, e seu conceito foi introduzido por Yamada, Matui e Sugiyama (1994) e Entani, Maeda e Tanaka (2002) e adotado por Lins, De Lyra Novaes e Legey (2005). 0 seu uso como método de aumento à discriminação é feito por Angulo-Meza et al. (2005) e Soares de Mello et al. (2008b). Este método avalia a ineficiência de uma DMU construindo uma fronteira constituída pelas unidades com as piores práticas gerenciais, chamada de fronteira ineficiente. As projeções das DMUs na fronteira invertida indicam um antialvo que é a combinação linear de anti-benchmarks. Portanto, a fronteira invertida também será utilizada para identificar as companhias aéreas com as piores práticas gerenciais.

Para o cálculo da fronteira de ineficiência é feita uma troca dos inputs com os outputs do modelo DEA original. A Figura 1 mostra as duas fronteiras, a clássica e a invertida, para o caso DEA BCC.

Tal como foi mencionado, a avaliação da fronteira invertida pode ser empregada como forma de contornar o problema da baixa discriminação em DEA e a fim de ordenar as DMUs. Calcula-se um índice de eficiência agregado (SOARES DE MELLO et al., 2008b), conforme descrito na Equação 2, que é a média aritmética entre a eficiência em relação à fronteira original e a ineficiência em relação à fronteira invertida. Esse índice de eficiência pode ser apresentado de forma normalizada - basta dividir todos os valores pelo maior índice calculado. Assim, para uma DMU ter máxima eficiência composta, ela precisa ter bom desempenho na fronteira padrão e não ter bom desempenho na fronteira invertida. Isso implica que a DMU seja boa naquelas características em que tem bom desempenho e não seja tão ruim naquelas em que seu desempenho não é dos melhores.

$\begin{aligned} & \text { Eficiência } \\ & \text { composta }\end{aligned}=\frac{\text { eficiência padrão }+(1-\text { eficiência invertida })}{2}$

\section{Avaliação das companhias aéreas brasileiras}

0 período escolhido para essa avaliação das companhias aéreas brasileiras foi o ano de 2007, que sucedeu uma grande crise no setor de transporte aéreo, causada principalmente pela falência de uma grande companhia aérea, a Varig, pela queda do avião da Gol e pelos problemas gerados pela falta de investimentos em infraestrutura de controle de tráfego aéreo. A partir deste momento, a concorrência entre as empresas se tornou mais acirrada.

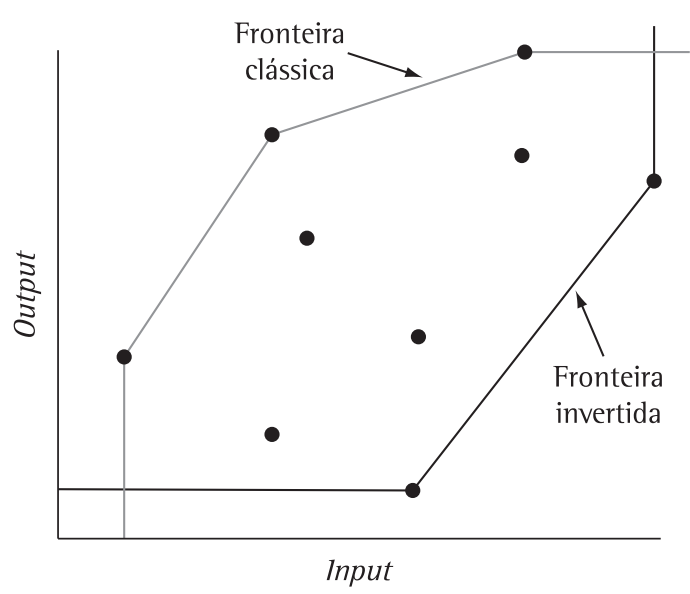

Figura 1. Fronteira DEA BCC clássica e invertida.

Assim, serão aplicadas a metodologia DEA e a fronteira invertida às companhias aéreas em operação no ano de 2007, com o objetivo de comparar os resultados obtidos nos dois métodos. Além disso, serão identificadas as empresas que apresentaram as melhores práticas, ou seja, as companhias pertencentes à fronteira de eficiência, e as companhias com as piores práticas (companhias pertencentes à fronteira de ineficiência).

Destaque-se que são raros os estudos de eficiência em empresas aéreas. Entre as companhias brasileiras, foram encontrados três estudos sobre eficiência operacional (SOARES DE MELLO et al., 2003; ARAÚJO et al., 2006; CORREIA; SOARES DE MELLO, 2009) e outros três que usam DEA para analisar a estrutura de capital dessas empresas (FERNANDES; CAPOBIANCO, 2001; CAPOBIANCO; FERNANDES, 2004; FERNANDES et al., 2008). No que tange ao transporte aéreo, a ferramenta DEA é mais usada para estudar eficiências de aeroportos (FERNANDES; PACHECO, 2002; PACHECO; FERNANDES, 2003; SOARES DE MELLO; GOMES, 2004; PACHECO; FERNANDES; SANTOS, 2006).

Este estudo visa avaliar o desempenho das companhias aéreas no que tange à sua gestão operacional. Para isso, como um dos inputs do modelo (recursos utilizados por cada companhia para operacionalização do serviço), considerou-se o principal bem de capital dessas empresas: as aeronaves. Porém, como as aeronaves usadas são de modelos diferentes, e consequentemente têm capacidades de transporte diferentes, foi utilizado como variável o peso máximo de decolagem de cada companhia, conforme proposto por Correia e Soares de Mello (2009). De fato, o peso máximo de decolagem engloba o peso do avião e do combustível (o que não gera receitas), mais o peso da carga transportada e o peso dos passageiros (o que gera receitas). 
Além disso, é preciso pessoal para operar as aeronaves, executar os serviços de apoio e gerir a empresa. Com isso, o outro input utilizado foi o total de pessoal de cada empresa. Destaque-se que o combustível poderia ser utilizado como outro input. No entanto, a Anac deixou de divulgar o total de combustível gasto por cada empresa. Ademais, Soares de Mello et al. (2003) mostraram que o uso dessa variável distorce os resultados, identificando um número muito grande de empresas como eficientes.

As empresas transportam passageiros e carga, e recebem por esse transporte, logo os outputs devem estar vinculados a essas duas variáveis. Por outro lado, não basta transportar - o transporte aéreo caracteriza-se por transportar a longas distâncias. Assim, foram escolhidos como outputs o número de assentos utilizados.quilômetros, e toneladas utilizadas.quilômetros.

Devido à diferença de tamanho entre as companhias aéreas e como não há garantia sobre a proporcionalidade entre inputs (capacidade da frota e total de pessoal) e outputs (passageiros. quilômetros utilizados e toneladas.quilômetros utilizados) escolheu-se o modelo DEA BCC com orientação à input, pois considera retornos variáveis de escala e orientação a inputs para verificar se a companhia está adequadamente dimensionada em relação ao transporte que realiza. Assim, entende-se que para longas distâncias o aproveitamento das aeronaves é maior.

Os dados foram obtidos no Anuário Estatístico do Transporte Aéreo divulgado pela Agência Nacional de Aviação Civil (2008). Esse estudo considerou os dados disponíveis do ano de 2007 por serem os mais recentes na ocasião em que foi realizado. Destaque-se que os anuários da Anac fornecem dados referentes ao final do ano. Assim, embora não saibamos o comportamento da frota ao longo do ano, pode-se estimar a frota média a partir dos dados no início do ano (frota do fim do ano anterior) e do fim do ano.

\section{Resultados}

0 modelo DEA-BCC clássico foi aplicado às 23 DMUs que representam as empresas brasileiras de transporte aéreo regular com movimentação de carga e passageiros no ano de 2007. Para melhorar a discriminação das companhias e identificar a melhor, foi aplicado o método da fronteira invertida. 0 software SIAD, de Angulo-Meza et al. (2005), calcula as eficiências clássicas e invertidas para cada DMU. Os resultados podem ser encontrados na Tabela 1.
Revelando a estrutura benevolente do método clássico, houve "empates", tendo-se quatro eficientes no ano de 2007 (ABSA Aerolineas Brasileiras, Gol Transportes Aéreos, Mega Transportes Aéreos e TAM Linhas Aéreas). Como não foi possível saber a companhia mais eficiente somente pelo cálculo da eficiência clássica, o método da fronteira invertida foi aplicado, e em seguida calculou-se a eficiência composta, a partir dos dois resultados anteriores, o que permitiu identificar assim a melhor companhia neste ano.

Os resultados apontam que a única DMU que se manteve eficiente (pela eficiência composta) foi a ABSA - Aerolineas Brasileiras. A comparação entre os resultados do DEA BCC clássico e da eficiência pela fronteira invertida permite observar a não benevolência deste último, pois a TAM, que havia sido avaliada como eficiente no modelo clássico, teve eficiência composta de apenas 0,639.

AABSA teve o melhor desempenho nas avaliações realizadas: $\mathrm{BCC}$ clássico e fronteira invertida. Dessa forma, percebe-se que essa empresa teve o melhor aproveitamento de seus recursos e transportou com eficiência suas cargas.

Segundo o portal de informações de empresas do setor aéreo Aviação Brasil (2009), a TAF (segunda companhia no ranking), em 2007, implementou novos canais de venda, o que melhorou o atendimento ao cliente, aumentando o nível de vendas. Dessa forma, o total de passageiros.quilômetros utilizados teve um aumento neste ano, impactando na sua avaliação final.

Com o encerramento das operações do Grupo Varig (Varig, Rio Sul e Nordeste) em 2006, houve uma concentração significativa em torno de duas empresas, Gol e TAM. Pode-se perceber que, em 2007, a TAM, embora tenha sido eficiente no modelo clássico, não obteve bons resultados no aproveitamento de seus recursos. Isso pode ser explicado pelo fato de que o mercado, em si, não estava preparado para a falência do Grupo Varig, reduzindo-se assim os níveis de serviço das companhias que absorveram alguns desses clientes.

0 mesmo ocorreu com a Gol, e dessa forma a empresa esteve empatada com a TAM e com a Mega em segundo lugar, de acordo com a avaliação da fronteira composta.

A Mega é uma empresa regional que atua apenas em algumas cidades do Norte, Nordeste e CentroOeste. No ano de 2007, teve o melhor desempenho dentre as companhias regionais.

Para a identificação dos benchmarks das companhias avaliadas neste ano foi utilizado o softwareSIAD, que verifica as DMUs que se localizam na fronteira eficiente do modelo BCC clássico e as torna referência para as demais ineficientes. Os benchmarks identificados estão apresentados na Tabela 2. 
Tabela 1. Eficiências clássicas, na fronteira invertida e composta.

\begin{tabular}{ccccc}
\hline $\begin{array}{c}\text { Companhias aéreas } \\
\text { brasileiras em 2007 }\end{array}$ & $\begin{array}{c}\text { Eficiência } \\
\text { clássica }\end{array}$ & $\begin{array}{c}\text { Eficiência } \\
\text { invertida }\end{array}$ & $\begin{array}{c}\text { Eficiência } \\
\text { composta }\end{array}$ & $\begin{array}{c}\text { Eficiência composta } \\
\text { normalizada }\end{array}$ \\
\hline ABSA & 1,000 & 0,566 & 0,783 & 1,000 \\
TAF & 0,759 & 0,530 & 0,644 & 0,823 \\
ABAETÉ & 0,833 & 0,273 & 0,553 & 0,706 \\
GOL & 1,000 & 0,000 & 0,539 \\
MEGA & 1,000 & 0,000 & 0,639 \\
TAM & 1,000 & 0,000 & 0,500 & 0,639 \\
RICO & 0,642 & 0,314 & 0,500 & 0,593 \\
MASTER TOP & 0,469 & 0,459 & 0,478 & 0,565 \\
WEBJET & 0,551 & 0,333 & 0,464 & 0,549 \\
PASSAREDO & 0,492 & 0,368 & 0,521 \\
VARIG & 0,816 & 0,000 & 0,442 & 0,456 \\
OCEANAIR & 0,631 & 0,083 & 0,430 & 0,452 \\
VARIG LOG & 0,707 & 0,000 & 0,408 & 0,361 \\
PUMA AIR & 0,229 & 0,336 & 0,357 & 0,271 \\
TRIP & 0,338 & 0,087 & 0,354 & 0,246 \\
SETE & 0,267 & 0,119 & 0,282 & 0,227 \\
NHT & 0,249 & 0,106 & 0,213 & 0,213 \\
SKYMASTER & 0,334 & 0,000 & 0,193 & 0,198 \\
META & 0,311 & 0,000 & 0,178 & 0,160 \\
PANTANAL & 0,250 & 0,000 & 0,167 & 0,139 \\
TEAM & 0,218 & 0,000 & 0,155 & 0,138 \\
TOTAL & 0,216 & 0,000 & 0,125 & 0,101 \\
AIR MINAS & 0,157 & 0,000 & 0,109 & 0,108 \\
\hline
\end{tabular}

Tabela 2. Benchmarks das companhias aéreas de 2007.

\begin{tabular}{|c|c|c|c|c|}
\hline $\begin{array}{l}\text { Companhias aéreas } \\
\text { brasileiras em } 2007\end{array}$ & \multicolumn{4}{|c|}{ Benchmarks } \\
\hline ABAETÉ & MEGA & TAM & & \\
\hline ABSA & ABSA & & & \\
\hline AIR MINAS & MEGA & TAM & $\mathrm{GOL}$ & \\
\hline $\mathrm{GOL}$ & GOL & & & \\
\hline MASTER TOP & MEGA & ABSA & & \\
\hline MEGA & MEGA & & & \\
\hline META & MEGA & $\mathrm{GOL}$ & & \\
\hline NHT & MEGA & $\mathrm{GOL}$ & & \\
\hline OCEANAIR & MEGA & TAM & & \\
\hline PANTANAL & MEGA & $\mathrm{GOL}$ & & \\
\hline PASSAREDO & MEGA & GOL & & \\
\hline PUMA AIR & MEGA & $\mathrm{GOL}$ & TAM & \\
\hline RICO & MEGA & TAM & & \\
\hline SETE & MEGA & GOL & & \\
\hline SKYMASTER & MEGA & ABSA & & \\
\hline TAF & MEGA & ABSA & TAM & \\
\hline TAM & TAM & & & \\
\hline TEAM & MEGA & GOL & & \\
\hline TOTAL & MEGA & ABSA & TAM & GOL \\
\hline TRIP & MEGA & GOL & ABSA & \\
\hline VARIG & MEGA & ABSA & TAM & \\
\hline VARIG LOG & ABSA & TAM & & \\
\hline
\end{tabular}

A fronteira de eficiência no ano de 2007 é composta pelas companhias ABSA - Aerolineas Brasileiras, Gol Transportes Aéreos, Mega Transportes
Aéreos e TAM Linhas Aéreas. Essas companhias são os benchmarks para as demais ineficientes.

Com exceção das companhias eficientes e da Varig log, todas as companhias tiveram como principal benchmark a companhia Mega Transportes Aéreos. lsso ocorre porque grande parte destas companhias é de pequeno porte e opera regionalmente, características semelhantes às da Mega, sendo esta empresa o real benchmark para as companhias regionais e de pequeno e médio porte.

No caso das companhias OceanAir, Webjet e Varig, que embora sejam empresas de operação nacional e internacional também tiveram a Mega como principal benchmark, deve-se adotar os outros benchmarks apontados pelo software e que tenham o mesmo porte e mesmo tipo de operação das companhias citadas. Assim, para essas empresas o benchmark adequado seria a TAM, conforme identificado também pelo SIAD. Mesmo que no ano de 2007 tenha ocorrido o acidente com uma aeronave da empresa no aeroporto de Congonhas, vitimando 199 pessoas, a TAM neste mesmo ano apresentou uma ampliação de suas rotas e quantidade de voos, justificando sua representatividade no mercado do transporte aéreo nacional e internacional. Situações como essas poderiam ser resolvidas pelo modelo DEA categóricas (BANKER; MOREY, 1986); no entanto, modelos desse tipo não foram desenvolvidos para o caso de fronteira invertida e anti-benchmarks. 
Para as companhias que transportam exclusivamente cargas, como a Varig Log, a Master Top e a Sky Master, o benchmark apropriado seria a ABSA, por apresentar características de operação semelhantes. A ABSA tem mostrado grande crescimento na sua participação no mercado ao longo dos últimos anos, inclusive com a ampliação do total de rotas.

Para encontrar os anti-benchmarks, foi também utilizado o software SIAD, de forma que os dados foram inseridos de forma invertida em relação ao modelo clássico, sendo possível assim a determinação da fronteira ineficiente e, consequentemente, as companhias pertencentes a ela, os anti-benchmarks. Os resultados podem ser vistos na Tabela 3:

De acordo com os resultados obtidos, os anti-benchmarks das companhias deste ano, pode-se perceber que Gol, Mega e TAM, eficientes no modelo clássico, foram seus próprios anti-benchmarks. Assim, entende-se que essas empresas estão localizadas tanto na fronteira eficiente quanto na ineficiente, sendo intercessões entre essas duas fronteiras. Esse resultado decorre de problemas no modelo BCC, como explicado em Soares de Mello et al. (2008a), especificamente pelo fato de uma DMU com o maior valor de um dos outputs ser sempre eficiente independente dos valores das outras variáveis. Se uma DMU tiver maior valor em um dos outputs, ela está localizada na fronteira clássica; se tiver o menor valor num dos inputs está também localizada na fronteira invertida. Neste estudo de caso, companhias aéreas de grande porte podem estar localizadas nas duas fronteiras, tal como o caso da Gol e da TAM. Já com a Mega, aconteceu o oposto - ela pertence às duas fronteiras por ter o menor valor em pelo menos um dos inputs.

As duas companhias cargueiras que se encontram na fronteira de ineficiência são a Varig $\log$ e a Skymaster. A Varig $\log$ é o principal anti-benchmark para a ABSA, também cargueira e de mesmo porte, demonstrando queda significativa no nível de serviço das empresas que compunham o antigo Grupo Varig.

Desde 2005, a Skymaster é alvo de investigações judiciais por subfaturamento em licitação dos Correios. A empresa vinha apresentando prejuízos recorrentes e teve seu contrato cancelado. Nesse caso, teve a capacidade de suas aeronaves subutilizada e tornou-se o principal anti-benchmark para a Master Top, ambas cargueiras de pequeno porte.

As companhias regionais que se encontram na fronteira ineficiente são: Meta, Pantanal, Team e Air Minas. Essas empresas são referências das piores práticas para as demais companhias regionais.

A partir das análises do setor de aviação comercial, realizadas pelo portal Aviação Brasil, em 2006 a Meta assistiu a uma queda de 29,40\% do aproveitamento de suas aeronaves em relação ao ano de 2005. Em 2007, deixou de operar em três cidades: Breves, Monte Alegre e Porto de Móz. Percebe-se então uma queda na oferta de voos dessa empresa, bem como baixo aproveitamento de suas aeronaves, o que a indica como anti-benchmark, especialmente no que se refere ao aproveitamento do peso máximo de decolagem e ao total de assentos.quilômetros transportados.

Segundo notícia publicada pelo Diário de Cuiabá, em 1/3/2008, no ano de 2007 a Pantanal passou por sérias dificuldades gerenciais, caracterizadas por atrasos no pagamento de salários e descumprimento de cláusulas da convenção coletiva dos trabalhadores. lsso explica o mau desempenho da companhia neste ano, justificando sua identificação como anti-benchmark, principalmente no que se refere à administração de pessoas.

A Air Minas é uma pequena companhia aérea, que iniciou suas atividades em 2006, com voos entre Belo Horizonte-Divinópolis-Varginha-Guarulhos. Em 2007, a empresa chegou a operar outras rotas, para as cidades de Cuiabá, Rondonópolis e São José dos Campos. Porém, nese mesmo ano, houve redução das cidades atendidas, iniciando 2008 com a operação em apenas três cidades: Belo Horizonte, Ipatinga e Uberlândia. A caracterização dessa companhia como anti-benchmarké justificada devido às dificuldades pelas quais a empresa tem passado no início de sua operação, tendo afetado o total de assentos.quilômetros transportados.

A Team é também uma pequena companhia, operando basicamente em algumas cidades do Rio de Janeiro. No ano de 2006, houve um acidente com uma aeronave da empresa, o que a obrigou a reduzir sua operação a apenas quatro cidades. Por ter apresentado redução no resultado de seus assentos.quilômetros transportados, a companhia é identificada como anti-benchmark.

Para as companhias nacionais e internacionais como a Webjet, TAF e OceanAir, os anti-benchmarks são as companhias Total e Varig. A Total, em 2007, passou por um processo de transição, justificado pela fusão com a companhia TRIP. Esse processo de mudança afetou os resultados da empresa neste ano de forma negativa, contribuindo para que a companhia estivesse localizada na fronteira ineficiente.

0 mau desempenho operacional da Varig no ano de 2007 é ainda reflexo da falência da empresa em 2006, o que gerou uma série de demissões e de reduções no número de rotas e voos. Assim, a companhia ainda não conseguiu recuperar-se dos problemas passados e foi indicada como anti-benchmark pelo modelo aplicado neste estudo. 
Tabela 3. Anti-Benchmarks das companhias aéreas de 2007.

\begin{tabular}{|c|c|c|c|c|}
\hline \multirow{2}{*}{$\begin{array}{l}\begin{array}{c}\text { Companhias aéreas } \\
\text { brasileiras em } 2007\end{array} \\
\text { ABAETÉ }\end{array}$} & \multicolumn{4}{|c|}{ Anti-Benchmarks } \\
\hline & TEAM & & & \\
\hline ABSA & VARIG LOG & SKY MASTER & & \\
\hline AIR MINAS & AIR MINAS & & & \\
\hline $\mathrm{GOL}$ & $\mathrm{GOL}$ & & & \\
\hline MASTER TOP & SKY MASTER & VARIG LOG & & \\
\hline MEGA & MEGA & & & \\
\hline META & META & & & \\
\hline NHT & TEAM & AIR MINAS & META & \\
\hline OCEANAIR & TOTAL & VARIG & & \\
\hline PANTANAL & PANTANAL & & & \\
\hline PASSAREDO & META & PANTANAL & & \\
\hline PUMA AIR & AIR MINAS & TEAM & META & SKY MASTER \\
\hline RICO & AIR MINAS & PANTANAL & VARIG & \\
\hline SETE & TEAM & META & AIR MINAS & SKY MASTER \\
\hline SKYMASTER & SKY MASTER & & & \\
\hline TAF & SKY MASTER & TOTAL & VARIG & VARIG LOG \\
\hline TAM & TAM & & & \\
\hline TEAM & TEAM & & & \\
\hline TOTAL & TOTAL & & & \\
\hline TRIP & PANTANAL & TOTAL & & \\
\hline VARIG & VARIG LOG & & & \\
\hline VARIG LOG & VARIG & & & \\
\hline WEBJET & TOTAL & PANTANAL & & \\
\hline
\end{tabular}

\section{Conclusões}

No presente estudo foi utilizada a Análise Envoltória de Dados (DEA) para a avaliação das companhias aéreas no ano de 2007 , no que tange aos aspectos operacionais. 0 objetivo do artigo de identificar a melhor companhia aérea do ano foi atingido através da aplicação da fronteira invertida, que permitiu avaliar também os pontos em que o desempenho da DMU não foi tão bom. Assim, a fronteira composta (obtida a partir da eficiência clássica e da eficiência invertida) indicou a companhia com melhor desempenho. Dessa forma, o método utilizado não permite que uma empresa atinja a eficiência somente devido a sua especialização. Isso explica o baixo desempenho de algumas companhias eficientes no modelo DEA clássico quando avaliadas pela fronteira invertida.

No ano de 2007, destaca-se o desempenho de duas companhias: Mega e TAF. A Mega, que iniciou suas atividades em 2005, foi eficiente no modelo DEA clássico e manteve-se nas primeiras posições após a aplicação da fronteira invertida. Assim, pode-se perceber a boa gestão de recursos realizada por esta empresa nesse período inicial de sua operação, fator fundamental para sobrevivência nesse mercado competitivo.
A TAF também apresentou bom desempenho, principalmente após a aplicação do método de discriminação. Isso pode ser explicado pelas diversas estratégias de marketing desenvolvidas pela empresa neste ano.

Além disso, a fronteira invertida permitiu a identificação de anti-benchmarks para as companhias aéreas em cada setor (cargas, regionais, etc.).

Cabe destacar também que existe um grande potencial de pesquisa no que se refere ao desempenho operacional no transporte aéreo, já que não existem muitos estudos com esse enfoque. Grande parte da avaliação das companhias aéreas baseia-se nos resultados econômico-financeiros dessas empresas, sem considerar os aspectos operacionais que geraram esses resultados. Além disso, o método aqui apresentado para determinação de benchmarks e anti-benchmark deve ser aprimorado a fim de que seja mais preciso. Da forma como foi utilizado, sem uma sofisticação adicional, o método permitiu que uma DMU fosse considerada simultaneamente benchmarke anti-benchmark para outra. Esse resultado, contrário ao senso comum, é consequência de alguns paradoxos do modelo BCC tal como explicado anteriormente. É esse tipo de resultado contrário ao senso comum que futuras técnicas mais aprimoradas deverão evitar. 


\section{Referências}

ADLER, N.; FRIEDMAN, L.; SINUANY-STERN, Z. Review of ranking methods in the data envelopment analysis context. European Journal of Operational Research, v. 140, n. 2, p. 249-65, 2002.

AGÊNCIA NACIONAL DE AVIAÇÃO CIVIL - ANAC. Anuários Estatísticos do Transporte Aéreo. 2008. Disponivel em: <http://www.anac.gov.br/>. Acesso em: abr. 2009.

ANGULO-MEZA, L. et al. ISYDS - Integrated System for Decision Support (SIAD Sistema Integrado de Apoio a Decisão): A Software Package for Data Envelopment Analysis Model. Pesquisa Operacional, v. 25, n. 3, p. 493-503, 2005.

ANGULO-MEZA, L.; LINS, M. P. E. Review of methods for increasing discrimination in Data Envelopment Analysis. Annals of Operations Research, v. 116, n. 1-4, p. 225-42, 2002.

ARAÚJO, A. H. et al. Eficiência e Desempenho do Transporte Aéreo Regional Brasileiro. Rio de Janeiro: SPOLM, 2006.

AVIAÇÃO BRASIL. Notícias. 2009. Disponível em: <www. aviacaobrasil.com.br>. Acesso em: Maio 2009.

BANKER, R. D.; CHARNES, A.; COOPER, W. W. Some models for estimating technical scale inefficiencies in data envelopment analysis. Management Science, v. 30, n. 9, p. 1078-92, 1984.

BANKER, R. D., MOREY, R. C. Use of Categorical Variables in Data Envelopment Analysis. Management Science, v. 32, n. 12, p. 1613-27, 1986.

CAPOBIANCO, H. M. P.; FERNANDES, E. Capital structure in the world airline industry. Transportation Research Part a-Policy and Practice, v. 38, n. 6, p. 421-34, 2004.

CHARNES, A.; COOPER, W. W.; RHODES, E. Measuring the efficiency of decision-making units. European Journal of Operational Research, v. 2, n. 6, p. 429-44, 1978.

COELHO, R. A Construção da agenda de desregulamentação do setor de transporte aéreo no Brasil. In: ANPET, 16., 2002, Natal. Anais... p. 383-394.

CORREIA, T. C. V. D.; SOARES DE MELLO, J. C. C. B. Avaliação da eficiência das companhias aéreas brasileiras com modelo DEA nebuloso. In: CONFEDERAÇÃO NACIONAL DO TRANSPORTE (Ed.). Transporte em Transformação XIII. Brasília, DF: Gráfica Positiva, 2009. p. 199-215.

ENTANI, T.; MAEDA, Y.; TANAKA, H. Dual models of interval DEA and its extensions to interval data. European Journal of Operational Research, v. 136, p. 32-45, 2002.

EVANGELHO, F.; HUSE, C.; LINHARES, A. Market entry of a low cost airline and impacts on the Brazilian business travelers. Journal of Air Transport Management, v. 11, n. 2, p. 99-105, 2005.
FERNANDES, E. et al. Financial performance of air transport companies. An analysis of the non-Pareto-efficient space in data envelopment analysis. WIT Transactions on Information and Communication Technologies, 2008. 185-94 p.

FERNANDES, E.; CAPOBIANCO, H. M. P. Airline capital structure and returns. Journal of Air Transport Management, v. 7, n. 3, p. 137-42, 2001.

FERNANDES, E.; PACHECO, R. R. Efficient use of airport capacity. Transportation Research Part a-Policy and Practice, v. 36, n. 3, p. 225-38, 2002.

LINS, M. P. E.; DE LYRA NOVAES, L. F.; LEGEY, L. F. L. Real estate appraisal: A double perspective data envelopment analysis approach. Annals of Operations Research, v. 138, n. 1, p. 79-96, 2005.

OLIVEIRA, A. V. M. A experiência brasileira na desregulamentação do transporte aéreo: um balanço e propositura de diretrizes para novas políticas. SEAE/MF, 2007. (Documento de Trabalho, 45).

PACHECO, R. R.; FERNANDES, E. Managerial efficiency of Brazilian airports. Transportation Research Part a-Policy and Practice, v. 37, n. 8, p. 667-80, 2003.

PACHECO, R. R.; FERNANDES, E.; SANTOS, M. P. D. Management style and airport performance in Brazil. Journal of Air Transport Management, v. 12, n. 6, p. 324-30, 2006.

SOARES DE MELLO, J. C. C. B. et al. Análise de envoltória de dados no estudo da eficiência e dos benchmarks para companhias aéreas brasileiras. Pesquisa Operacional, v. 23, n. 2, p. 325-45, 2003.

SOARES DE MELLO, J. C. C. B. et al. Alguns paradoxos em modelos DEA-BCC: eficiências negativas e inexistência de retornos de escala. In: ENCONTRO NACIONAL DE ENGENHARIA DE PRODUÇÃO, 28., 2008, Rio de Janeiro. Anais... Rio de Janeiro: ABEPRO, 2008a.

SOARES DE MELLO, J. C. C. B. et al. DEA Advanced Models for Geometric Evaluation of used Lathes. WSEAS Transactions on Systems, v. 7, n. 5, p. 500-20, 2008b.

SOARES DE MELlO, J. C. C. B.; GOMES, E. G. Eficiências aeroportuárias: uma abordagem comparativa com análise de envoltória de dados. Revista de Economia e Administração, v. 3, n. 1, p. 15-23, 2004.

YAMADA, Y.; MATUI, T.; SUGIYAMA, M. New analysis of efficiency based on DEA. Journal of the Operations Research Society of Japan, v. 37, p. 158-67, 1994.

\section{Agradecimentos}

À CAPES, ao CNPq e à FAPERJ pelo apoio financeiro.

\section{Use of DEA and inverted frontier for airlines benchmarking and anti-benchmarking identification}

\section{Abstract}

The increase of the air transportation sector competition in recent years has changed this market dynamics, leading airlines to seek new strategies to ensure their position. This article aims to analyze the performance of Brazilian air carriers regarding their operational management after the crisis of the sector in 2006. The analysis of the companies' efficiency in 2007 is done by comparing the results obtained with a classic DEA model to those obtained with the lnverted Frontier method. This paper includes the identification of the airlines with the best and the worst managerial practices.

\section{Keywords}

Air transport. Data envelopment analysis. Benchmarking. 